\author{
УДК 338.45
}

Кривов Г. А. ${ }^{1}$, Матвиенко В. А. ${ }^{1}$, Рудъко А. Н. ${ }^{1}$, Хохотва В. В. ${ }^{1}$, Читак В. ${ }^{2}{ }^{2}$, Двейрин А. $3 .{ }^{2}$, Романович Г. $\mathrm{H}^{2}$

${ }^{1}$ АО «Украинский научно-исследовательский институт авиационной технологии». Украина, г. Киев

${ }^{2}$ Государственное предприятие «АНТОНОВ». Украина, г. Киев

\title{
ИНФОРМАЦИОННО-АНАЛИТИЧЕСКАЯ БАЗА ДЛЯ РОЗРАБОТКИ МЕТОДИЧЕСКИХ МАТЕРИАЛОВ ПО ПРОГНОЗИРОВАНИЮ И УКРУПНЕННЫМ РАСЧЕТАМ СЕБЕСТОИМОСТИ ГРАЖДАНСКИХ САМОЛЕТОВ НОВОГО ПОКОЛЕНИЯ В СЕРИЙНОМ ПРОИЗВОДСТВЕ
}

\begin{abstract}
В статье представлена информация иллюстрирующая внимание, которое уделяют ведущие мировые производители, проблеме управления затратами при реализации программ создания пассажирских и транспортных самолетов. Отмечается особая важность корректной оценки затрат на начальных стадиях реализации проектов, когда принимается большинство концептуальных решений, определяющих уровень затрат на проект в целом. Представлены результаты проведенного авторами аналитического обзора отечественных и зарубежных публикаций, посвященных оценке затрат на разработку и серийное производство самолетов разных поколений. Сформулировано видение авторов относительно планируемых к разработке методик оценки затрат на создание отечественных гражданских самолетов. [dx.doi.org/10.29010/89.11]
\end{abstract}

Ключевые слова: методика; себестоимость самолета; затраты на разработку, производство; экономикоматематическая модель.

В опубликованных ранее работах специалистов УкрНИИАТ [1-5] отмечалось, что одной из основных тенденций развития мировой авиационной промышленности на современном этапе является консолидация авиастроительного бизнеса, проявляющаяся в слиянии партнеров и поглощении конкурирующих компаний, сокращении избыточных производственных мощностей, образовании крупных финансово-промышленных объединений. В гражданском самолетостроении наибольших успехов достигли компании сократившие затраты на разработку и производство самолетов за счет внедрения новых эффективных методов и систем проектирования, производства и сопровождения в эксплуатации самолетов.

Как свидетельствует мировой опыт, стоимость гражданских авиационных программ имеет устойчивую тенденцию к повышению. Наиболее успешно реализуются те программы, для инвестирования которых удается объединить собственные средства головного разработчика-изготовителя нового самолета и корпоративные средства компаний-поставщиков комплектующих изделий, материалов, полуфабрикатов, государственные заказы, инвестиции финансовых структур, средства будущих владельцев-эксплуатантов самолетов.

Анализ деятельности авиастроительных компаний свидетельствуют о том, что успех свойственен тем программам гражданского самолетостроения, в которых удавалось эффективно сформулировать их цели, объективно оценить затраты на всех этапах реализации программы и достичь запланированных в них технических и экономических показателей. Ведущие мировые производители авиационной техники выделяют проблему управления затратами в число первых приоритетов в процессе создания новых самолетов, в частности, на начальных стадиях проектов [6-10]. Это объясняется тем, что на этих стадиях принимается подавляющее большинство концептуальных решений, определяющих уровень затрат на реализацию проекта в целом (рис. 1).

Советская нормативно-методическая база оценки затрат на разработку и производство самолетов включает несколько общеотраслевых методик [1117], разработанных в 1980-1990 г.г. и не отражающих реалии и особенности современного этапа развития мирового и отечественного самолетостроения.

Ниже представлены результаты проведенного авторами аналитического обзора открытых публикаций, содержащих информацию, которую целесообразно принять во внимание при разработке методических материалов (ММ) по прогнозированию и укрупненному расчету себестоимости новых гражданских самолетов в серийном производстве на начальных этапах их жизненного цикла. 
СТОИМОСТЬ ЖИЗНЕННОГО ЦИКЛА

ТИПИЧНОГО ИЗДЕЛИЯ НАУКОЕМКОГО МАШИНОСТРОЕНИЯ

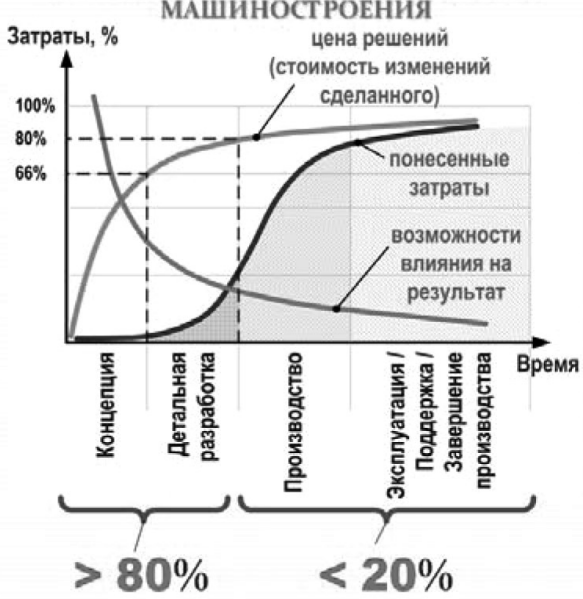

возможности влияния на результаты
- $>80 \%$ возможности влияния на

результаты, в том числе на затраты

Производства и затраты Потребителя

сосредоточены на первых двух стадиях

жизненного цикла Изделия: Концепция

и Детальная разработка

- $<20 \%$ возможности влияния на

результаты относится к стадии

жизненного цикла Изделия

Прочзводство

Рис. 1. Возможности влияния на стоимость жизненного цикла изделия наукоемкого машиностроения [21]

В настоящее время для определения себестоимости самолетов различных классов, в т.ч. пассажирских и военно-транспортных, существует ряд методик, методических материалов и справочнонормативных материалов [16-24], которые обеспечивают расчет себестоимости самолета в серийном производстве в целом и по следующим основным составляющим:

- затраты на разработку самолета;

- затраты на подготовку производства;

- затраты на производство самолета.

При этом советские и отечественные методики [16-19] дают возможность определять себестоимость самолета на ранних стадиях его проектирования, без учета затрат на его разработку и подготовку производства.

Эти методики обеспечивают расчет затрат на производство самолета любого порядкового номера как в целом, так и по отдельным составляющим, с разной степенью детализации, а именно:

- методики [16-18] - по таким составляющим как собственные расходы, расходы на материалы и покупные комплектующие изделия (ПКИ), двигатели и внепроизводственные расходы;

- методика [19] - по существующей в авиационной промышленности, типовой структуре затрат (затраты на сырье, материалы и полуфабрикаты; ПКИ; затраты на оплату труда ОПР и т.д.).

В методиках [16-19] использован параметрический метод оценки затрат. Это фактически экономико-математические модели (ЭММ), которые для оценки различных элементов затрат или себестоимости самолета в целом используют определенную взаимосвязь одного или нескольких физических (эксплуатационных) параметров летательного аппарата с затратами на его разработку и производство.
Исходными данными для методик [16-19] являются:

- масса пустого самолета, структура массы;

- максимальная скорость полета;

- программа выпуска самолетов (общая и годовая);

- сухая масса двигателя;

- мощность двигателя;

- количество двигателей.

В качестве примера, представлена ЭММ расчета одной из составляющих затрат на производство самолета, применяемая в методике [17, с. 715], а именно: собственных затрат предприятия:

$$
3_{\mathrm{c}}=\mathrm{A} \cdot G^{\lambda 1} \cdot V^{\lambda 2} \cdot N^{-\lambda 3} \cdot i^{\lambda 4} \cdot K_{\mathrm{o}} \cdot K_{\tau},
$$

где A - постоянная величина, выражающая величину собственных расходов для данного класса самолетов при значении факторов, равных $1 ; G$ - масса пустого самолета; $V$ - максимальная скорость полета на установленной ТТЗ высоте; $N$ - порядковый номер самолета с начала серийного производства, который соответствует году, для которого устанавливается ориентировочная себестоимость; $i$ - время от выпуска первого самолета к самолету с порядковым номером $N ; \lambda 1, \lambda 2, \lambda 3, \lambda 4-$ параметры модели; $K_{0}-$ коэффициент увеличения затрат, учитывающий отчисления в фонд освоения новой техники (для гражданских самолетов); $K_{\tau}-$ корректирующий коэффициент, учитывающий изменения закономерности формирования собственных расходов во времени. Значение этого коэффициента определяются моделью:

$$
K_{\tau}=a+b \cdot t,
$$


где $a, b$ - постоянные коэффициенты; $t$ - число лет от года, принятого за базу, до года производства самолета с порядковым номером $N$.

Наибольшее влияние на величину себестоимости самолета, в применяемых в методиках [16-19] экономико-математических моделях, оказывает масса пустого самолета, его скорость, а также удельная масса двигателя ( $\left.\frac{\text { кг }}{\text { кгс тяги }}\right)$.

Среди других особенностей советских и отечественных методик следует отметить:

- валюта себестоимости - рубли СССР;

- отсутствие учета влияния инфляции, роста цен на ПКИ и материалы на величину себестоимости самолета;

- исходные данные, на основе которых были разработаны методики, отражают технологический уровень производства 1960...1970-х годов;

- учет составляющих себестоимости, которые не используются в настоящее время: обязательность отчисления в Фонд освоения новой техники, учет доплаты к заработной плате по районному коэффициенту;

- в методике [18, с. 141] расчет заводских расходов основан на использовании большого количества коэффициентов, размер которых определен на основе статистических данных одного предприятия и соответственно учитывают особенности структуры себестоимости самолета именно для этого предприятия, что значительно ограничивает сферу применения этой методики.

В отличии от советских и отечественных методик, иностранные методики позволяют определять себестоимость самолета на ранних стадиях его проектирования как в целом, так и с оценкой необходимых затрат на разработку, технологическую подготовку производства и производство самолета. При этом, можно выделить два типа методик:

1. Методики [20-22] основаны на параметрических методах оценки затрат, с использованием таких исходных данных как: масса пустого самолета, максимальная скорость полета, сухая масса двигателя, программа выпуска самолетов и т.п. (подобно отечественным и советским методикам);

2. Методика [23] основана на использовании данных об удельных затратах на разработку и производство одного фунта массы пустого самолета.

Особенностью методики [20] является то, что она разработана RAND Corporation в 1987 г. (так называемая модель DAPCA) для использования при планировании и оценке программ военных самолетов ВВС США. Она позволяет рассчитывать себестоимость самолета на ранних стадиях его проектирования с оценкой затрат по следующим составляющим:

- стоимость разработки конструкции самолета;

• стоимость технологической оснастки;
- фонд оплаты труда;

- стоимость ПКИ, материалов и полуфабрикатов;

- стоимость технологической и конструкторской поддержки разработки;

- стоимость летных испытаний;

- стоимость контроля качества.

Поскольку данные, на основе которых разрабатывалась методика, собирались у производителей военных самолетов, ЭММ используемые в этой методике, больше подходят для расчета себестоимости именно военных самолетов, а не коммерческих. При этом, расчеты себестоимости самолета осуществляются в долларах США на 1977 год.

К недостаткам этой методики следует также отнести:

- отсутствие учета особенностей самолетов по назначению, массе и т.п.;

- отсутствие учета сложности программы, типов материалов, которые использовались при конструировании самолета, а также года его выпуска;

- использование единиц измерения, отличных от системы СИ.

Методика [21] была разработана в 1990 г. и предназначена как для оценок программ военного, так и гражданского самолета. При этом, расчет затрат на разработку и производство самолета осуществляется по составляющим, приведенным на рис. 2.

Особое внимание авторами этой методики было уделено обеспечению достаточной чувствительности предложенной модели оценки затрат к ряду факторов, связанных с реализацией проекта, а именно:

- сложности проекта;

- использованию систем автоматизированного проектирования;

- типу материалов, используемых при конструировании самолета;

- необходимости постройки новых объектов для тестирования и моделирования;

- различию в затратах на оборудование салона самолета.

При этом методикой предусматривается наличие информации о стоимости двигателей и авионики.

Наибольшее влияние на себестоимость самолета в этих ЭММ оказывает масса планера самолета и максимальная скорость полета. В свою очередь, размер программы выпуска самолетов оказывает существенное влияние на стоимость материалов, рабочей силы и летных испытаний.

Методика [22] была разработана в 2012 г. и предусматривает расчет цены и себестоимости самолета на ранних стадиях его проектирования, с оценкой необходимых затрат на разработку и отдельно на производство самолета. Для определения этих затрат заложена методология с нисходящим подходом, приведенная на рис. 3.

На первом этапе определяется цена самолета на основе нелинейного регрессионного анализа зави- 


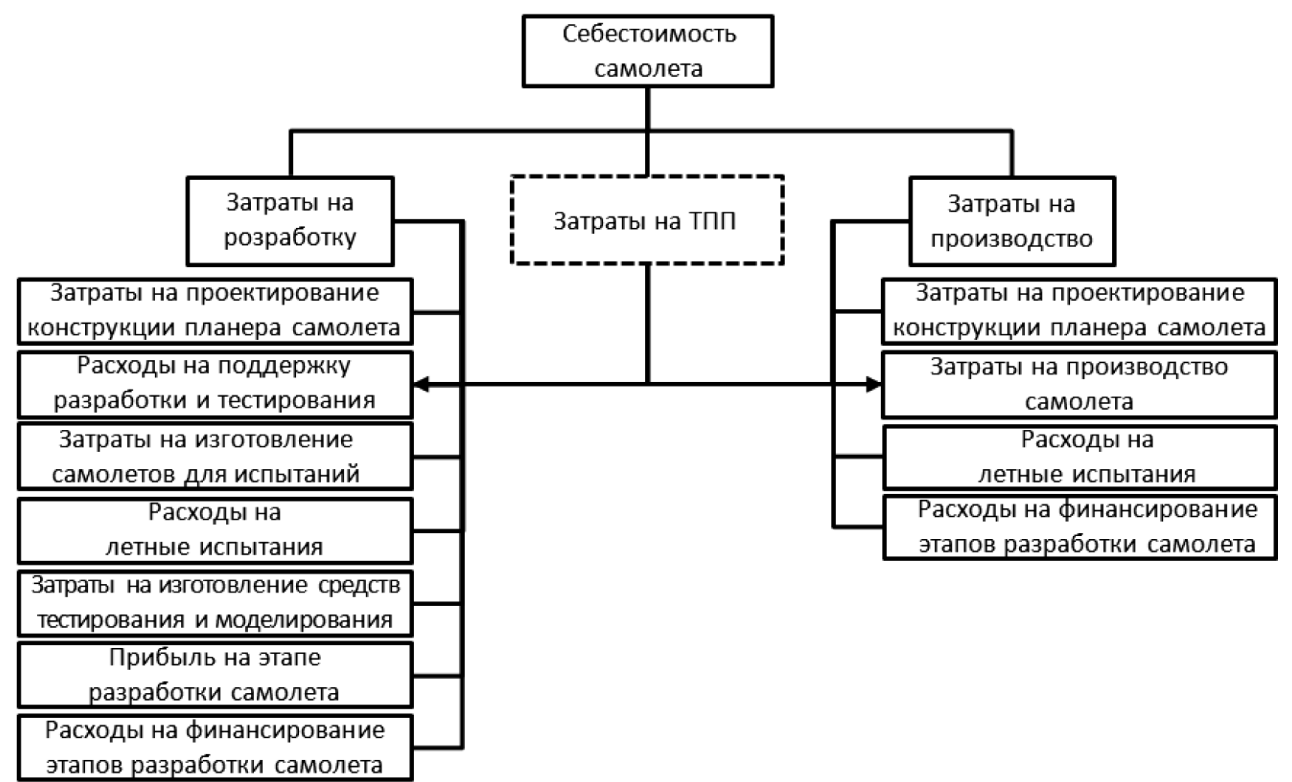

Pис. 2. Структура затрат на разработку и производство самолетов, определяемая методикой Roskam [21]

симости цены самолета от его различных конструктивных параметров. При этом определяется предельный размер себестоимости самолета, с учетом прибыли и возможной скидки. В дальнейшем, в себестоимости самолета выделяют затраты на разработку, производство и затраты, связанные с привлечением инвестиций (выплата процентов по кредитам и т.п.) которые определяются с использованием раннее разработанных методик.

Так, затраты на разработку определяются с использованием методики Roskam [21]. При этом точность модели улучшена за счет внедрения коэффициента общности, учитывающего снижение затрат за счет использования в новой модели уже разработанных и освоенных элементов конструкции самолета. Определение коэффициента основы- вается на разделении затрат на разработку самолета по его основным типовым составляющим (рис. 3).

Для оценки затрат на производство самолета используется модель Beltramo [24], которая позволяет рассчитывать затраты на производство отдельных агрегатов самолета используя данные о весе агрегата и программе выпуска самолетов.

Инвестиционные расходы зависят от процентных ставок и размера заимствований, которые планируется осуществить для реализации программы. Для ЭММ принятой в этой методике был избран упрощенный подход, который предполагает постоянные процентные ставки в течение периода кредитования.

В дальнейшем, с целью оптимизации проекта и достижения целевых показателей принимаются

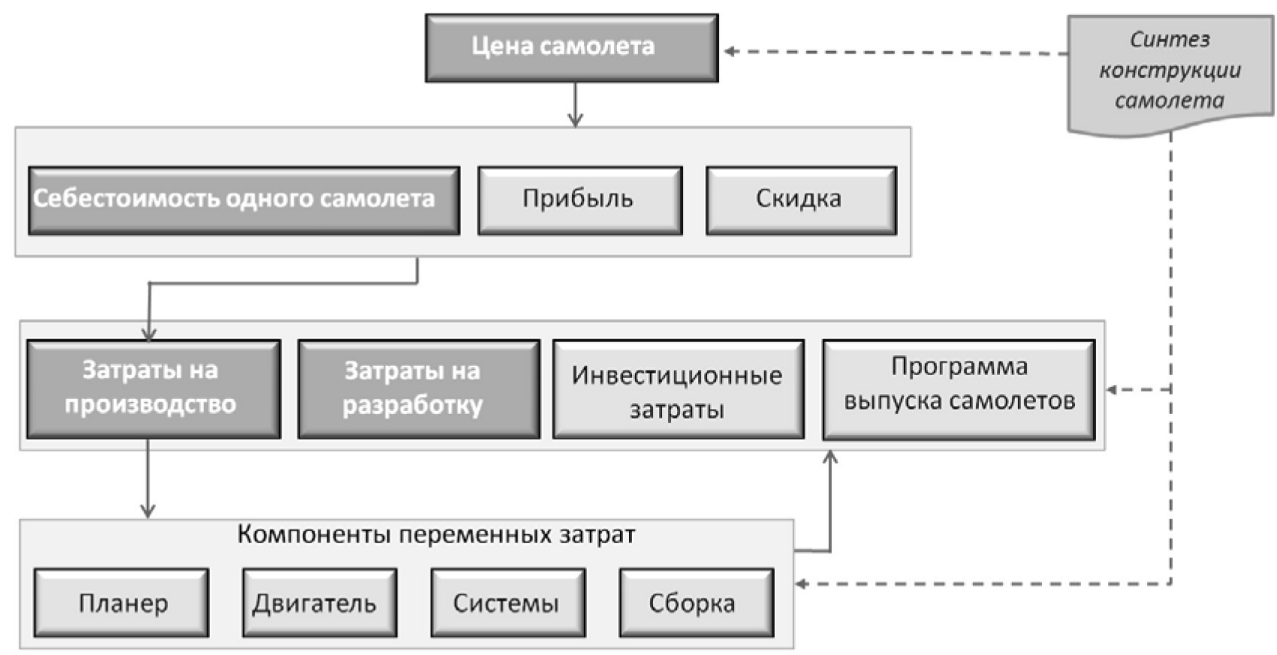

Рис. 3. Структура модели расчета стоимости самолета [22] 
решения относительно внесения изменений в параметры конструкции самолета, программы производства и т.п. с последующим проведением повторных расчетов.

Методика [23] была разработана в 2002 году и основана на наличии данных об удельных затратах на разработку и производство одного фунта массы пустого самолета. Данный подход применяется для расчета стоимости разработки и производства отдельных агрегатов самолета с учетом разделения затрат на следующие составляющие:

- на этапе разработки самолета:

- разработка конструкции;

- разработка технологических процессов изготовления самолета;

- проектирование средств технологической оснастки;

- изготовление средств технологической оснастки;

• испытания и сертификация;

- на этапе производства:

- оплата труда;

- материальные затраты;

- другие затраты.

При этом, в методику расчета заложена структура массы типового коммерческого самолета, приведенная на рис. 4.

Кроме этого, методика учитывает эффект кривой обучения при определении затрат на производство самолета, а также снижение себестоимости самолета за счет использования готовых решений, реализованных в самолетах-прототипах и разработанных ранее отдельных агрегатах самолета.

Таким образом, данные об удельных затратах на разработку и производство одного фунта массы пустого самолета могут применяться для расчета стоимости разработки любого элемента конструкции нового самолета, предполагая, что все компоненты нового самолета классифицированы по принятой в этой методике структуре, а также наличие оценок массы каждого агрегата самолета. Полная себестоимость разработки или производства самолета будет определяться путем суммирования затрат на разработку или производство каждого агрегата самолета.

Следует отметить, что использование отдельных положений этой методики, в рамках разработки современной ЭММ расчета себестоимости самолета, требует учета различий в структурах затрат на производство самолета. Так, при расчетах в методике [23] стоимости производства одного фунта массы пустого самолета учитывались особенности структуры себестоимости самолета для американских и европейских авиастроительных предприятий. На наших же отечественных предприятиях структура затрат на производство самолета существенно отличается, что вызывает необходимость внесения определенных корректив в вышеупомянутые показатели.

К недостаткам этой методики следует также отнести:

- отсутствие информации относительно исходных данных, на основе которых была разработана методика;

- отсутствие учета влияния инфляции, роста цен на ПКИ и материалы на величину себестоимости самолета;

- использование единиц измерения, отличных от системы СИ.

Учитывая изложенное выше, представляется возможным констатировать следующее:

- с учетом характера проблем, существующих в отечественном самолетостроении и возможных путей их поэтапного решения, одной из актуальных задач в исследуемой сфере является разработка методик прогнозирования и укрупненных расчетов себестоимости новых гражданских самолетов в серийном производстве на начальных этапах их жизненного цикла;

- необходимость создания актуализированной нормативно-методической базы оценки себестои-

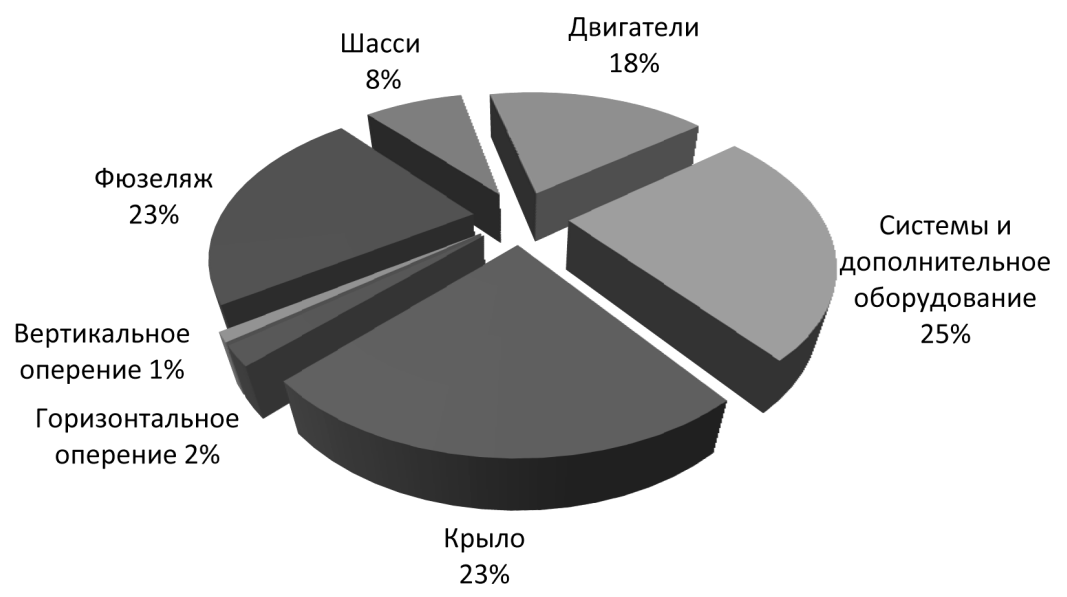

Рис. 4. Типовое распределение массы пустого коммерческого самолета по его основным составляющим 
мости производства отдельных составляющих и самолета в целом обусловлена все более очевидной целесообразностью интеграции украинского самолетостроения в международные проекты и программы.

В свою очередь, результаты проведенного авторами анализа вышеупомянутых методик свидетельствуют о невозможности использования ни одной из них в полном объеме (без внесения корректировок) в качестве системного методического пособия для расчета себестоимости самолета на ранних стадиях его проектирования.

По мнению авторов, новые ММ должны обеспечивать комплексность и полноту расчетов, позволяя при этом:

1. Обеспечивать на этапе разработки концептуального проекта методическую поддержку процедур прогнозирования:

1.1. Себестоимости самолета в целом;

1.2. Себестоимости самолета по его основным составляющим (затраты на разработку самолета; затраты на подготовку производства; затраты на производство самолета).

2. Обеспечивать на этапе разработки эскизного проекта методическую поддержку процедур укрупненных расчетов:

2.1. Затрат на разработку самолета по видам работ (проектирование конструкции планера самолета, изготовление опытных самолетов, испытания и сертификация);

2.2. Затрат на технологическую подготовку производства самолетов по видам работ (проектирование средств технологического оснащения (СТО), изготовление СТО, разработка технологических процессов изготовления самолета);

2.3. Затрат на производство самолета по составляющим (материалы и полуфабрикаты; покупные комплектующие изделия; двигатели; фонд оплаты труда; накладные общепроизводственные расходы);

2.4. Себестоимости отдельных агрегатов самолета (крыло, хвостовое оперение, фюзеляж, шасси, двигатели, системы, вспомогательное оборудование).

При этом целесообразно использовать, предварительно актуализировав, лишь общие подходы и отдельные положения проанализированных методик [16-24]:

- при прогнозировании себестоимости самолета - использовать подход на основе удельных показателей себестоимости, с учетом отдельных положений методики [23];

- при укрупненных расчетах - с использованием параметрического способа на основе таких исходных данных как: масса пустого самолета, максимальная скорость полета, сухая масса двигателя, программа выпуска самолетов, а также с учетом отдельных положений соответствующих методик:

- [20, 21] - для затрат на разработку;

- [20, 21] - для затрат на ТПП;

- $[16,19,20,21,24]$ - для затрат на производство.

В разрабатываемых ММ целесообразно предусмотреть возможность расчета себестоимости самолета, как на текущий момент, так и на перспективу, с учетом планируемой программы выпуска самолетов, а также прогнозируемых изменений на рынке материальных и трудовых ресурсов. При этом, прогноз изменения рыночных условий может быть выполнен на основе анализа динамики изменения «Индекса цен производителей» на отечественном, европейском и американском рынках на протяжении последних 20 лет.

Одной из первоочередных задач, решение которой будет способствовать разработке актуализированных методик прогнозирования и укрупненных расчетов себестоимости самолетов нового поколения, является систематизация статистической информации, характеризующая объем, структуру фактических затрат, связанных с разработкой и производством самолетов предыдущих поколений.

В последующих публикациях планируется представить информацию, касающуюся результатов разработки авторами упомянутых выше методических материалов.

\section{Аббревиатура}

MМ - методические материалы

ПКИ - покупные комплектующие изделия

ЭММ - экономико-математическая модель

ОПР - основные производственные рабочие

TТ3 - тактико-техническое задание

СТО - средства технологического оснащения

ТПП - технологическая подготовка производства

\section{Литература}

[1] Кривов Г. А., Матвиенко В. А., Афанасьева Л. Ф. Мировая авиация на рубеже XX-XXI столетий. Промышленность, рынки. - К., 2003. - 296 с.

[2] Кривов Г. А., Матвиенко В. А., Щербак А. А., Щередина Т. Н. Гражданское самолетостроение в начале XXI столетия. Деятельность ведущих мировых производителей. - К.: КИТ, 2008. - 168 с.

[3] Кривов Г. А., Матвиенко В. А. Конкурентоспособность в современном авиастроении. Пути достижения и поддержания // Технологические системы. 2006. - № 2. - C. 16-22.

[4] Матвиенко В.А., Щербак А. А. Формирование и реализация программ создания гражданских самолетов нового поколения. Опыт ведущих зарубежных производителей // Технологические системы. 2005. - № 3. - C. 41-46. 
[5] Кривов Г.А. Стоимость - важнейший параметр проекта гражданского самолета и показатель его конкурентоспособности // Технологические системы. - 2009. - № 5(49). - С. 22-36.

[6] Лауль А. А. Некоторые проблемы конкуренции с западными партнерами в авиационных проектах России.//Авиационная промышленность. - 2000. № 2. - C. 95-100.

[7] M. Kaufman. Cost/weight optimization of aircraft structures./ Licentiate thesis. - 2008.

[8] C. E. Kim. Composites cost modeling: Complexity. - 1991.

[9] R. Curran, S. Raghunathan, M Price. Integrating aircraft cost modeling into conceptual design. - 2005 .

[10] K. Willcox. Cost analysis. MIT Aerospace Computational Design Laboratory. - September, 2004.

[11] Методика определения трудоемкости изготовления самолетов в серийном производстве. В кн.: Руководство по технологичности самолетных конструкций. - НИАТ. - 1983. - С. 707-710.

[12] Определение металлоемкости новых самолетов и стоимости материалов, расходуемых в серийном производстве. В кн.: Руководство по технологичности самолетных конструкций. - НИАТ. - 1983.

[13] Методика прогнозирования технологической трудоемкости серийного производства самолетов и газотурбинных двигателей. В кн.: Руководство по технологичности самолетных конструкций. - НИАТ. - 1972.

[14] Влияние степени освоения и серийного производства на затраты времени при выполнении операций. В кн.: Руководство по технологичности самолетных конструкций. - НИАТ. - 1972.

[15] Определение трудоемкости изготовления изделий с использованием статистических данных малого объема. Методический материал. ГИПРОНИИАВИАПРОМ. - 1982.

[16] Межведомственная методика и справочно-нормативные материалы для прогнозирования затрат на серийное производство самолетов гражданской авиации. - Москва: - НИИ экономики, планирования и управления. $-1982 .-68$ с.

[17] Определение себестоимости серийного производства и цены новых самолетов и вертолетов. Руководство по технологичности самолетных конструкций. Москва: - НИАТ, -1983. - С. 714-715.

[18] Бізнес-план ДК «АНТОНОВ», - 2005. - С. 141-147.

[19] Технико-экономическое обоснование конструкций самолетов и двигателей. - Харьков: - Нац. аэрокосм. ун-т «Харьк. авиац. ин-т». - 2000. - 51 с.

[20] Aircraft airframe cost estimating relationships. Study approach and conclusions / RAND Corporation, м. Санта-Моника, Каліфорнія, США. - 1987.

[21] J. Roskam, Airplane Cost Estimation: Design. Development. Manufacturing and Operating, Pt. 8, Roskam Aviation and Engineering Corporation, Lawrence, KS. -1990.

[22] T. Lammering, K. Franz, Aircraft Cost Model for Preliminary Design Synthesis / Institute of Aeronautics and Astronautics, RWTH Aachen University, - Germany. -2012.

[23] J. Markish, Valuation Techniques for Commercial Aircraft Program Design / Massachusetts Institute of Technology. - 2002.

[24] M. N. Beltramo, D. L. Trapp, B. W. Kimoto, D. P. Marsh, Parametric study of transport aircraft systems cost and weight / Douglas Aircraft Company, Los Angeless. 1977.

Krivov G. A. ${ }^{1}$, Matvienko V. A. ${ }^{1}$, Rudko A. N. ${ }^{1}$, Khokhotva V. V. ${ }^{1}$, Chitak V. G. ${ }^{2}$, Dveirin A. Z. ${ }^{2}$, Romanovich G. N. ${ }^{2}$

${ }^{1}$ Ukrainian Research Institute of Aviation Technology, JSC. Ukraine, Kiev

${ }^{2}$ ANTONOV, State-owned Enterprise. Ukraine, Kiev

\section{INFORMATION AND ANALYTICAL BASE FOR THE DEVELOPMENT OF METHODOLOGICAL MATERIALS FOR THE COST ESTIMATING OF THE NEW GENERATION CIVIL AIRCRAFT IN THE SERIAL PRODUCTION}

The article focuses on the relevance of the problem of cost management in the civil aircraft production programs. At the same time, the importance of estimating expenses at the initial stages of their implementation is emphasized, when the vast majority of conceptual decisions are taken that determine the level of costs for the project as a whole. The results of an analytical review of open access publication of domestic and foreign methods for estimating the expenses (costs) of the development and production of aircraft are presented. Conclusions are drawn regarding the possibility of their use in the development of methodological materials for estimating and an enlarged calculation of the cost of civil aircraft in serial production at the initial stages of their life cycle. [dx.doi.org/10.29010/89.11]

Keywords: methodology; the cost of the aircraft; development cost; production cost; cost-estimating relationship. 


\section{References}

[1] Krivov G. A., Matvienko V.A., Afanaseva L. F. Mirovaya aviaciya na rubezhe XX-XXI stoletij. Promyshlennost, rynki. - K., 2003. - $296 \mathrm{c}$.

[2] Krivov G. A., Matvienko V. A., Sherbak A. A., Sheredina T. N. Grazhdanskoe samoletostroenie v nachale XXI stoletiya. Deyatelnost vedushih mirovyh proizvoditelej. - K.: KIT, 2008. - 168 c.

[3] Krivov G. A., Matvienko V. A. Konkurentosposobnost v sovremennom aviastroenii. Puti dostizheniya i podderzhaniya // Tehnologicheskie sistemy. - 2006. - № 2. - C. 16-22.

[4] Matvienko V.A., Sherbak A. A. Formirovanie i realizaciya programm sozdaniya grazhdanskih samoletov novogo pokoleniya. Opyt vedushih zarubezhnyh proizvoditelej // Tehnologicheskie sistemy, - 2005. - № 3. - C. 41-46.

[5] Krivov G. A. Stoimost - vazhnejshij parametr proekta grazhdanskogo samoleta i pokazatel ego konkurentosposobnosti // Tehnologicheskie sistemy. - 2009. - № 5(49). - C. 22-36.

[6] Laul A. A. Nekotorye problemy konkurencii s zapadnymi partnerami v aviacionnyh proektah Rossii.//Aviacionnaya promyshlennost. - 2000. - № 2. - C. 95-100.

[7] M. Kaufman. Cost/weight optimization of aircraft structures./ Licentiate thesis. -2008.

[8] C. E. Kim. Composites cost modeling: Complexity. - 1991.

[9] R. Curran, S. Raghunathan, M Price. Integrating aircraft cost modeling into conceptual design. - 2005.

[10] K. Willcox. Cost analysis. MIT Aerospace Computational Design Laboratory. - September, 2004.

[11] Metodika opredeleniya trudoemkosti izgotovleniya samoletov v serijnom proizvodstve. V kn.: Rukovodstvo po tehnologichnosti samoletnyh konstrukcij. - NIAT. - 1983. - C. 707-710.

[12] Opredelenie metalloemkosti novyh samoletov i stoimosti materialov, rashoduemyh v serijnom proizvodstve. V kn.: Rukovodstvo po tehnologichnosti samoletnyh konstrukcij. - NIAT. - 1983.

[13] Metodika prognozirovaniya tehnologicheskoj trudoemkosti serijnogo proizvodstva samoletov i gazoturbinnyh dvigatelej. V kn.: Rukovodstvo po tehnologichnosti samoletnyh konstrukcij. - NIAT. - 1972.

[14] Vliyanie stepeni osvoeniya i serijnogo proizvodstva na zatraty vremeni pri vypolnenii operacij. V kn.: Rukovodstvo po tehnologichnosti samoletnyh konstrukcij. - NIAT. - 1972.

[15] Opredelenie trudoemkosti izgotovleniya izdelij s ispolzovaniem statisticheskih dannyh malogo obema. Metodicheskij material. GIPRONIIAVIAPROM. - 1982.

[16] Mezhvedomstvennaya metodika i spravochno-normativnye materialy dlya prognozirovaniya zatrat na serijnoe proizvodstvo samoletov grazhdanskoj aviacii. - Moskva: - NII ekonomiki, planirovaniya i upravleniya. - 1982. - 68 c.

[17] Opredelenie sebestoimosti serijnogo proizvodstva i ceny novyh samoletov i vertoletov. Rukovodstvo po tehnologichnosti samoletnyh konstrukcij.- Moskva: - NIAT. - 1983. - C. 714-715.

[18] Biznes-plan "ANTONOV". - 2005. - C. 141-147.

[19] Tehniko-ekonomicheskoe obosnovanie konstrukcij samoletov i dvigatelej. - Harkov: - Nac. aerokosm. un-t "Hark. aviac. in-t”. - 2000. $-51 \mathrm{c}$.

[20] Aircraft airframe cost estimating relationships. Study approach and conclusions / RAND Corporation, м. CaнтаМоника, Каліфорнія, США. - 1987.

[21] J. Roskam, Airplane Cost Estimation: Design. Development. Manufacturing and Operating, Pt. 8, Roskam Aviation and Engineering Corporation, Lawrence, KS. - 1990.

[22] T. Lammering, K. Franz, Aircraft Cost Model for Preliminary Design Synthesis / Institute of Aeronautics and Astronautics, RWTH Aachen University, - Germany. - 2012.

[23] J. Markish, Valuation Techniques for Commercial Aircraft Program Design / Massachusetts Institute of Technology.2002.

[24] M. N. Beltramo, D. L. Trapp, B. W. Kimoto, D. P. Marsh, Parametric study of transport aircraft systems cost and weight / Douglas Aircraft Company, Los Angeless. - 1977. 